SHORT REPORT

\title{
Evidence for autism in folklore?
}

\author{
J Leask, A Leask, N Silove
}

Arch Dis Child 2005;90:271. doi: 10.1136/adc.2003.044958

"The girl I gave birth to has been stolen, she's gone." (Mother, A Current Affair, Vaccination: a stab in the dark? 30 January 2001)

"So the goblins came. They pushed their way in and pulled baby out, leaving another all made of ice." (Maurice Sendak, Outside over there. Puffin Books, Middlesex, UK, 1981)

a $\mathrm{n}$ the wake of the now settled MMR controversy and attempts to link the vaccine with autism, there has been widening interest in whether autism has increased in incidence over the past two decades. ${ }^{12}$ While this question is yet to be fully resolved, folkloric heritage suggests the existence of autism long before its formal recognition in $1943 .^{3}$

Fairytales from the British Isles, Germany, and Scandinavia include stories about changelings. They describe a child who exhibits remarkable and sudden changes in behaviour and/or appearance, explaining that supernatural folk steal normal children and replace them with one of their own, or some other substitute. The new child-the changeling-is characterised by unresponsiveness, resistance to physical affection, obstreperousness, inability to express emotion, and unexplained crying and physical changes such as rigidity and deformity. Some are unable to speak.

Sometimes the fairies fancy mortals, and carry them away into their own country, leaving instead some sickly fairy child, or a log of wood so bewitched that it seems to be a mortal pining away, and dying, and being buried. Most commonly they steal children. ${ }^{4}$

The parallels between changeling tales and autism, have been briefly noted by writers on the history of the disorder. ${ }^{5}$ Some of the features of these stories, including the initial health and beauty of the human child, the change after some period of "normalcy", and the specific behaviours of the changeling (listed above) are well matched to symptoms in some presentations of autism.

Most tales of changelings contain instructions on how to prevent the child being stolen, ways of determining whether the child is a changeling, and instructions on how to manage their behaviour.

Commentators on changeling tales have concluded that the stories explained the birth of disabled children in non-scientific cultures. The legends were society's attempt to make sense of, and cope with, child disability, providing a coherent explanation for its occurrence. ${ }^{67}$

We suggest that evidence for the existence of autism before the twentieth century lends force to the argument that the disorder's existence is not just a product of recent technologies or the environments that these technologies have created. Whether such technologies have augmented an existing predisposition in some individuals remains to be resolved.

\section{ACKNOWLEDGEMENTS}

NCIRS is supported by The Commonwealth Department of Health and Ageing, The NSW Department of Health, and The Children's Hospital at Westmead.

\section{Authors' affiliations}

J Leask, National Centre for Immunisation Research and Surveillance of Vaccine Preventable Diseases, The Children's Hospital at Westmead and the University of Sydney, New South Wales, Australia

A Leask, Wentworth Area Health Service Population Health Unit, Penrith, New South Wales, Australia

N Silove, Child Development Unit, The Children's Hospital at Westmead and the University of Sydney, New South Wales, Australia

Competing interests: none declared

Correspondence to: Dr J Leask, National Centre for Immunisation Research and Surveillance of Vaccine Preventable Diseases (NCIRS), Locked Bag 4001, Westmead, NSW 2145, Australia;

JulieL3@chw.edu.au

Accepted 24 September 2004

\section{REFERENCES}

1 Fombonne E. Is there an epidemic of autism? Pediatrics 2001;107:411-13.

2 Lingam R, Simmons A, Andrews N, et al. Prevalence of autism and parentally reported triggers in a north east London population. Arch Dis Child 2003;88:666-70.

3 Kanner L. Autistic disturbances of affective contact. Nerv Child 1943;2:217-50.

4 Yeats WB. Fairy and folk tales of Ireland, 2nd edn. Gerrards Cross: Smythe, 1973.

5 Wing L. The history of ideas on autism. Autism 1997;1:13-23.

6 Ashliman DL. Changelings. http://www.pitt.edu/ dash/changeling.html\#1. 1997 (accessed 23 October 2003).

7 Windling T. Changelings. Journal of Mythic Arts [serial online] Spring 2003 (accessed 21 October 2003). 